\title{
Socioeconomics drive urban plant diversity
}

\author{
Diane Hope*†, Corinna Gries*, Weixing Zhu, William F. Fagan§, Charles L. Redmanๆ, Nancy B. Grimm, Amy L. Nelson", \\ Chris Martin**, and Ann Kinzig"
}

*Center for Environmental Studies, Arizona State University, Tempe, AZ 85287-3211; ${ }^{\ddagger}$ Department of Biological Sciences, Binghamton University,

State University of New York, Binghamton, NY 13902-6000; §Department of Biology, University of Maryland, College Park, MD 20742;

"Department of Biology, Arizona State University, Tempe, AZ 85287-1501; "Alliance Data Systems, Gahanna, OH 43230-5318; and

**Department of Plant Biology, Arizona State University, Tempe, AZ 85287-1601

Edited by Peter Vitousek, Stanford University, Stanford, CA, and approved May 20, 2003 (received for review December 11, 2002)

Spatial variation in plant diversity has been attributed to heterogeneity in resource availability for many ecosystems. However, urbanization has resulted in entire landscapes that are now occupied by plant communities wholly created by humans, in which diversity may reflect social, economic, and cultural influences in addition to those recognized by traditional ecological theory. Here we use data from a probability-based survey to explore the variation in plant diversity across a large metropolitan area using spatial statistical analyses that incorporate biotic, abiotic, and human variables. Our prediction for the city was that land use, along with distance from urban center, would replace the dominantly geomorphic controls on spatial variation in plant diversity in the surrounding undeveloped Sonoran desert. However, in addition to elevation and current and former land use, family income and housing age best explained the observed variation in plant diversity across the city. We conclude that a functional relationship, which we term the "luxury effect," may link human resource abundance (wealth) and plant diversity in urban ecosystems. This connection may be influenced by education, institutional control, and culture, and merits further study.

C ities represent extreme cases of human influence on ecosystem function (1-3) and provide unique opportunities for integrating humans into ecology (4-6). Spatial variation in plant diversity has been attributed to heterogeneity in resource availability for many ecosystems (7). However, urbanization has resulted in entire landscapes that are now occupied by plant communities wholly created by humans $(8,9)$. Hence in and around cities, plant diversity may reflect social, economic, and cultural influences as well as those recognized by traditional ecological theory. To date, urban ecosystem characteristics have been evaluated largely in terms of the urban-to-rural gradient paradigm (10-13), with the simple linear gradient concept evolving to include gradients of disturbance, land-use intensity, and the polycentric, anisotropic nature of modern cities $(14,15)$. However, such studies typically focus on patches of native vegetation within cities (16-19) rather than the full range of land-use types with their human-created plant communities that characterize much of the urban landscape. In addition, conceptual developments have identified the need to quantify gradients of resource availability and disturbance that integrate land use, legacy effects, socioeconomic status, and cultural differences, because these may mediate the human-environment interaction and influence resultant ecological conditions (20-24).

We focused on spatial variation in plant diversity across the Central Arizona-Phoenix region because plant diversity is an important determinant of overall ecosystem biodiversity that influences the composition and abundance of associated biota (25). We asked how well a suite of biotic, abiotic, and humanrelated variables explain site-to-site variations in richness of perennial plant genera (including both exotics and natives). The focus on perennials allowed us to eliminate seasonal variation that might have arisen over the course of the field survey. Spatial variation in plant diversity across unmanaged ecosystems at the regional scale in arid landscapes is typically related to geomorphic controls on water and nutrient supply $(26,27)$. Our pre- diction for the Central Arizona-Phoenix region was that predominantly geomorphic (elevation) controls on diversity in undeveloped native Sonoran desert vegetation outside the city $(28,29)$ would be replaced by land use as the primary correlate of spatial variation in plant diversity across the city $(30,31)$ along with a possibility of some variation due to distance from urban center $(15,32)$.

\section{Materials and Methods}

Study Area and Sampling Design. We surveyed perennial plant generic richness across the entire Central Arizona-Phoenix long-term ecological research study area, which covers 6,400 $\mathrm{km}^{2}$, includes the rapidly expanding metropolitan Phoenix area, surrounding agricultural, and undeveloped native desert land, and contains 3 million people. Using a dual-density, randomized, tessellation-stratified design, we obtained a spatially dispersed, unbiased sample that allowed for maximum postdesign stratification. Probability-based sampling has been used in a number of national and regional studies $(33,34)$ because it ensures representative and unbiased characterization of ecological resources $(35,36)$, but application of this technique to a large urban area is unique. The dual-density tessellation-stratified design consisted of a grid of $4 \times 4-\mathrm{km}$ squares, on which was superimposed the "beltway" of existing and proposed freeways that encircles the main developed parts of the Phoenix metropolitan area. To allow for the much greater landscape heterogeneity within the developed metropolitan core (32), we used a sampling density inside/outside the developed urban core of 3:1, with a random sample taken in every square inside and one sample in every third square (chosen randomly) outside that area; this gave an equal number of $\approx 100$ samples inside and 100 samples outside the developed urban core, giving a total sample size of 206. Access was negotiated successfully for all but eight sites; six of these plots were relocated to the nearest (within $100 \mathrm{~m}$ ) similar accessible site. There were only two samples to which access was denied and no suitable surrogate could be found, giving a total of 204 sites surveyed.

Field Survey. A synoptic integrated field inventory was carried out between late February and early May 2000. The sampling unit used was a $30 \times 30-\mathrm{m}$ plot, in which all perennial woody vegetation was mapped, measured, and identified. Because the appearance of many horticultural cultivars can make accurate identification to the level of species difficult, plants were identified to species where possible or to genera where not but was standardized at the level of genus for subsequent analysis. However, in most study plots plant diversity on the genus level corresponds closely to diversity at the species level except in the case of two desert genera (Ambrosia and Cylindropuntia), of which there were two or three species present in $\approx 30$ plots. Each site was also mapped to delineate the cover of the main surface types (e.g., asphalt, concrete, bare soil, and turf) on the $900-\mathrm{m}^{2}$

This paper was submitted directly (Track II) to the PNAS office.

tTo whom correspondence should be addressed. E-mail: dihope@asu.edu. 
plot; these data were used to calculate the percent impervious surface cover at each site. Soil core samples $(2.54 \mathrm{~cm}$ in diameter) were collected by using an impactor corer at four randomly determined locations within each plot at the 0 - to $10-\mathrm{cm}$ depth interval and combined to give a single sample from each survey site. These samples were sieved (2-mm mesh) seem homogenized, and a 10-g subsample was extracted with $2 \mathrm{M} \mathrm{KCl}$ solution; the filtered extract was acidified, stored at $4^{\circ} \mathrm{C}$, and analyzed for nitrate- $\mathrm{N}\left(\mathrm{NO}_{3}-\mathrm{N}\right)$ on a Bran-Luebbe TrAAcs 800 autoanalyzer by using the calcium reduction method within 2 weeks as part of the chemical and physical characterization of the soils across the region. Land use at each of the 204 surveyed sites was classified according to a modified version of the Maricopa Association of Governments land-use classification scheme (37). The five main land-use categories were urban $(n=91)$, desert $(n=73)$, agriculture $(n=23)$, transportation $(n=6)$, and a "mixed" class $(n=11)$. This classification differs from the Maricopa Association of Governments scheme in two main ways. First, managed "open" space within the urban area (i.e., irrigated parks, sports fields) was subsumed as a subcategory under the "urban" top-level category. Second, it differs by the addition of the mixed category for sites where more than one of the main land uses was present in the same survey plot.

Supplemental Data. Data from the field survey were supplemented with several additional key geographic and socioeconomic variables, which consisted of the latitude and longitude used to locate each site, defined by using the Universal Transverse Mercator North American Datum 27 projection. Also, elevation was included, as derived from the United States Geological Survey Digital Elevation Model for the region. Distance of each site from the urban center (defined as Central Avenue and Washington Street) and from the nearest major freeway were calculated by using ARCVIEW GIS. In addition, historic land-use analyses carried out for each survey point (38) were used to determine the number of years each site had been in agricultural use as well as to assign an indicator variable showing whether the site had ever been in agriculture. Three socioeconomic variables (median family income, median age of housing stock, and human population density) were taken from the U.S. Census of Population and Housing for the appropriate block group within which each survey point was located. Census block groups are drawn up to standardize the size of the human population within a certain range and approximate to a neighborhood. Within the developed urban core the average block group size was $5.3 \mathrm{~km}^{2}$ and were mostly paired with sample sites: Only $17 \%$ of the urban sites fell in a block group with another site. Outside the developed core the human population is sparser and block groups are considerably larger (average $168 \mathrm{~km}^{2}$ ); $86 \%$ of desert sites occurred in a block group with one or more other sites. Hence, block groups varied in size and were necessarily coarser than the size of the field survey plots but constitute the smallest unit for which socioeconomic information were readily available. Moreover, because clear human influences are only directly relevant for the urban model, where the Census block group data well represent the neighborhoods surrounding our survey sites, we do not consider the census block groups too large to invalidate our conclusions. Additional variables collected during the field survey but not used in the analyses presented here included physical (e.g., bulk density and soil textural analysis) and chemical (e.g., ammonium-N, total N, organic C, inorganic $\mathrm{C}$, total $\mathrm{C}$, and $\mathrm{pH}$ ) characterization; sample collection to determine arthropod, pollen, and prokaryote diversity; mapping and measurement of all permanent, built structures; and documentary photographs in the four cardinal directions.

Statistical Analyses. A total of 13 variables were chosen to represent the main geophysical, geographic, and human char- acteristics of the study site and to have minimal colinearity (latitude, longitude, elevation, land use, distance from urban center, distance from nearest major freeway, impervious surface cover, soil nitrate- $\mathrm{N}$ concentration, number of years in agriculture, whether ever in agriculture, population density, median housing age, and median family income). Spatial variation in perennial plant generic richness was modeled across the whole region as well as separately for the undeveloped desert sites and developed urban sites (of which just over half were in private residential yards) by using a suite of spatial statistical techniques and these independent variables. The selection of the final model in each case primarily depended on the probability distribution used to model the response variable. Because plant diversity were count data (number of woody plant genera per plot), generalized linear modeling techniques were used with a log link and Poisson probability distribution. Pearson residuals revealed no spatial autocorrelation for data from all sites and from the urban-only sites. Generalized linear models were fit, but due to overdispersion, quasilikelihood techniques were applied. Deviance residuals were examined to investigate potential outliers. For the desert sites, the semivariogram of the Pearson residuals indicated spatial autocorrelation in the errors. A spherical semivariogram was fit to the empirical semivariogram of residuals obtained from the ordinary least squares model of the number of woody plant genera (which was square-roottransformed to stabilize the variance). Variance inflation factors between the independent variables used in these analyses never exceeded seven, and most were substantially less, indicating that colinearity is not a significant problem. When making inferences about the parameters, we used an $\alpha=0.05$ significance level unless noted otherwise. We do not report $r^{2}$ values for the resultant models, because in generalized linear modeling there is no statistic that is the counterpart of the $r^{2}$ value in regression. Instead, the test statistic and significance level are given for each variable in each model to indicate the marginal effect, i.e., the strength of each the contribution of the variable given that all the other variables are included.

\section{Results and Discussion}

Spatial variation in plant diversity across the entire Central Arizona-Phoenix region (Fig. 1) was explained best by a combination of land use, elevation, median family income, and whether the site had ever been farmed (Table 1). The importance of land use (particularly urban and agricultural) as a determinant of overall plant diversity supports the expected relationship between patch type and ecological condition (30, 31). Urban landscapes across the Phoenix metropolitan area have been established in the presence of a low-cost, abundant water supply, native plants having been replaced with imported exotic genera to create urban "oases" (39), a pattern typical of human settlement across the arid and semiarid regions of North America (40). This seems to have increased total generic plant richness ( $\gamma$ diversity) across the region as a whole, as has been reported for urbanized regions elsewhere (41, 42). However, local $(\alpha)$ diversity in perennial plant genera across the urban landscape is actually very similar to the native desert vegetation it replaced, albeit with considerably higher compositional turnover ( $\beta$ diversity) between urban sites comprised of many exotic genera (Table 2). The median family income for the whole study area was $\$ 50,750 /$ year. Plant diversity at sites in neighborhoods with incomes above this amount was on average twice that found in the landscapes of less wealthy areas (11 compared with 5 genera per plot). In addition, across the study region as a whole, sites that were formerly farmed had $43 \%$ fewer woody plant genera than locations that had never been cultivated.

Spatial variation in generic plant diversity among urban sites (which were an approximately equal mixture of private residential yards and other urban land uses, e.g., commercial, institu- 


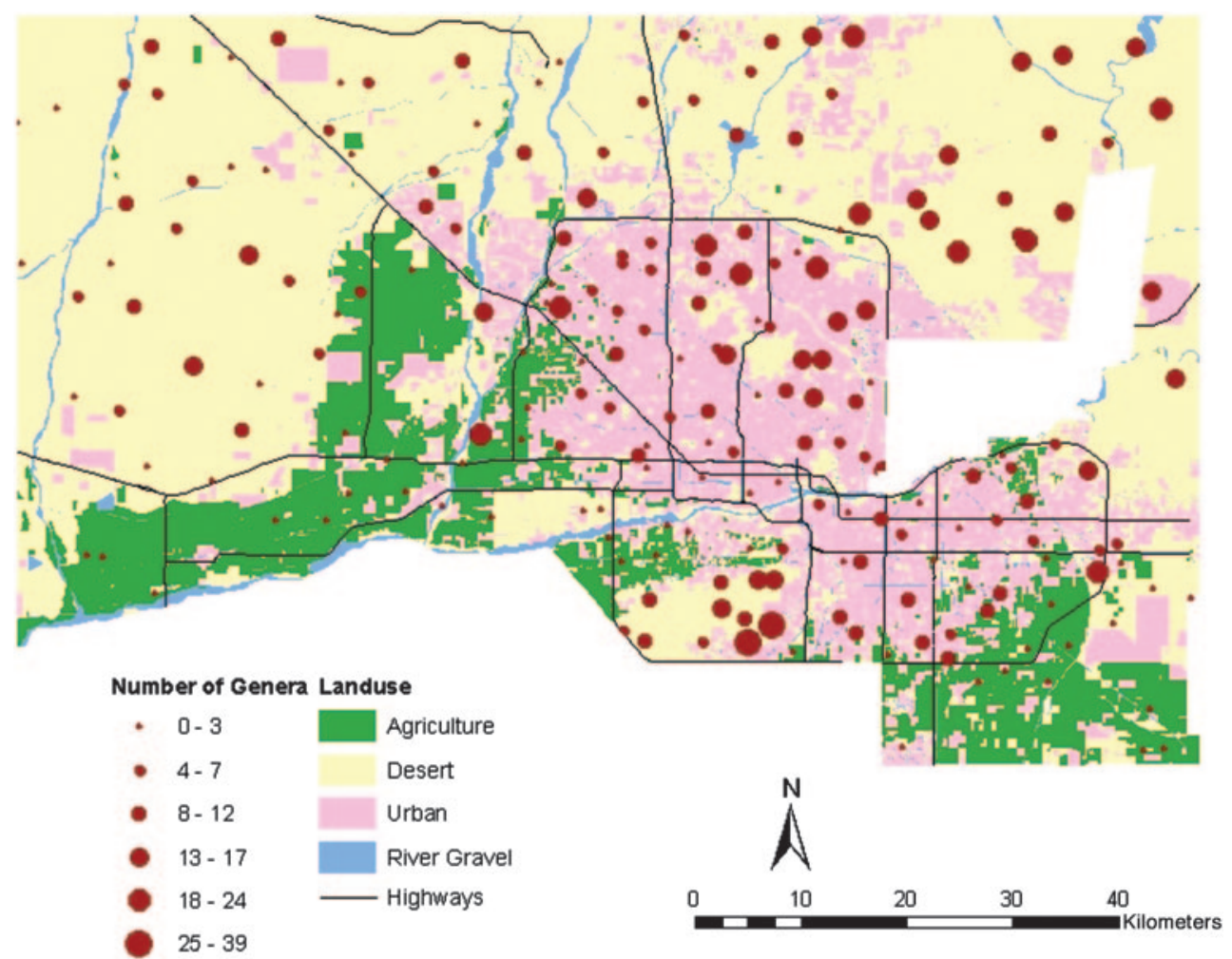

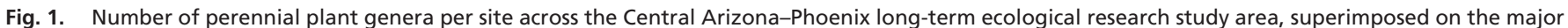

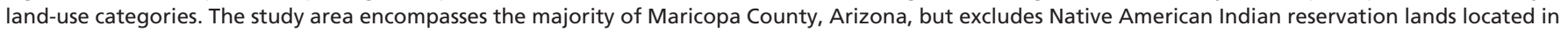
the east and to the south of the area shown.

tional, recreational, and industrial) was best predicted by human variables exclusively (Table 1). Plant diversity across the urban landscape was positively related to income in the surrounding area (Fig. 2). Wealthier neighborhoods are often located at higher elevations in metropolitan Phoenix, as in many American cities (43), and there was some colinearity between elevation and income (variance inflation factor $=0.506$ for the urban sites); hence, it was not possible to quantify the extent to which wealthier people create more diverse landscapes or simply acquire them. We term the relationship between wealth and plant diversity the "luxury effect," whereby as their economic wherewithal increases, humans occupy urban landscapes with higher plant diversity. Is this relationship a robust one given the rapidly changing landscape of the Central Arizona-Phoenix study region? For example, might median family incomes have changed differentially between block groups at time scales shorter than the lifetime of the woody perennials? We believe that this result is a robust one for two reasons. First, prior research has indicated that the composition and longevity of woody perennials in the Phoenix urban landscape is determined largely by human choices and landscape maintenance rather than by natural reproduction and mortality and thus tends to closely reflect current ownership preferences (44). Second, a comparison of the income data with those from 10 years previously in the same census block groups, showed that income increased evenly across census tracts. Moreover the relationship between wealth and plant diversity would also appear to be similar to the link seen between socioeconomic status, species composition, and physical structure of vegetation in residential yards in several other cities $(9,45-47)$, leading us to suggest that the relationship

Table 1. Best-fit models of plant diversity

\begin{tabular}{|c|c|c|c|}
\hline & All sites & Urban & Desert \\
\hline Model type & Spherical semivariogram & GLM & GLM \\
\hline Data transformation & Log link & Log link & Square root \\
\hline Spatial autocorrelation & Absent & Absent & Present \\
\hline \multirow[t]{6}{*}{ Predictor variables ${ }^{\dagger}$} & Land use & Family income $(8.08)^{*}$ & Elevation $(7.59) * * *$ \\
\hline & Urban $(27.35) * * *$ & Median housing age $(-6.65)$ * & Distance from urban center $(-2.89)$ * \\
\hline & Agriculture (10.21)* & Ever farmed (4.34) & Median housing age $(2.50)$ \\
\hline & Elevation $(24.88) * * *$ & & \\
\hline & Family income $(12.72) * *$ & & \\
\hline & Ever farmed (6.04) & & \\
\hline
\end{tabular}

\footnotetext{
Significant variables are listed in order of importance as judged by the level of significance denoted by asterisks $(* * *, P<0.0001$ $* *, P<0.001 ; *, P<0.01$; no asterisk, $P<0.05)$. GLM, generalized linear modeling.

${ }^{\dagger}$ The appropriate test statistics are shown in parentheses, consisting of $\chi^{2}$ values for all sites and urban models and a $T$ value for the desert model.
} 
Table 2. Summary statistics for plant diversity (number of perennial genera per site)

\begin{tabular}{lcccccc} 
& $\begin{array}{c}\text { All sites } \\
(n=204)\end{array}$ & $\begin{array}{c}\text { Urban } \\
(n=91)\end{array}$ & $\begin{array}{c}\text { Desert } \\
(n=73)\end{array}$ & $\begin{array}{c}\text { Agricultural } \\
(n=23)\end{array}$ & $\begin{array}{c}\text { Transportation } \\
(n=6)\end{array}$ & $\begin{array}{c}\text { Mixed } \\
(n=11)\end{array}$ \\
\hline Total $(\gamma$ diversity $)$ & 188 & 156 & 63 & 9 & 9 & 24 \\
Mean $(\alpha$ diversity $)$ & 6.8 & 8.0 & 8.4 & 0.5 & 1.5 & 2.8 \\
Median & 5 & 6 & 7 & 0 & 1 & 1 \\
SD & 6.5 & 7.1 & 5.5 & 1.3 & 1.8 & 3.5 \\
Range & $0-39$ & $0-39$ & $1-24$ & $0-5$ & $0-4$ & $0-8$ \\
$\beta$ diversity & 27.6 & 19.5 & 7.5 & 17.3 & 6.0 & 8.5 \\
\hline
\end{tabular}

between wealth and plant diversity may be characteristic of urban landscapes generally.

Plant diversity of developed urban sites was also related to age of housing, with higher diversity at sites with younger housing. We interpret this finding to reflect changes in landscape design, technology, and cultural values associated with more recent housing developments across the Phoenix metropolitan area. Before 1960 the predominant function of urban landscapes was to provide shading and evapotranspirational cooling, but the advent of widespread air conditioning and an increasing public interest in the conservation of native desert flora and water has resulted in a switch from broad expanses of grass and fastgrowing broadleaf deciduous shade trees to xeriscapes with a more diverse suite of desert-adapted trees and shrubs $(36,48)$. It may also be that wealthy people prefer newer housing, as indicated by weak colinearity between housing age and median family income (variance inflation factor $=-0.379$ for the urban sites) and that this also affects plant diversity in the urban landscape. Although the importance of air conditioning is specific to this region, we suggest that it represents an example of the underlying influence of technocultural controls, which may change among regions with different climatic regimes and cultural settings (49).

Elevation was a significant predictor of variation in plant diversity (Table 1) for both the undeveloped desert and the entire study region despite significant urbanization across the latter. The effect of elevation, along with the spatial autocorrelation in plant generic richness seen between neighboring samples at undeveloped desert sites up to a distance of $10 \mathrm{~km}$ apart, reflects the close correlation of plant communities to landform and geomorphic surfaces that previous studies have shown govern resource availability, in particular water and nutrient supply and hence underlying spatial variation in plant diversity at the regional scale in arid environments $(26,50)$. After

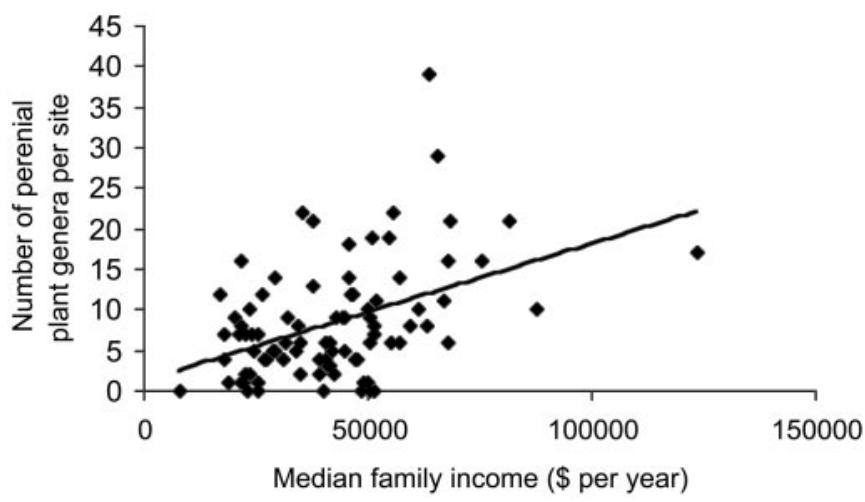

Fig. 2. Variation in the number of perennial plant genera with median family income (in dollars per year) from the U.S. Census of Population and Housing for the block group surrounding each survey site, at the urban sites. The regression line shown is an indicator of the linear relationship in the absence of the other predictor variables. accounting for spatial relatedness and elevation, perennial plant richness increased with proximity to the urban center, an effect that seems to be mainly due to several large floristically diverse remnants of upland Sonoran desert on mountain preserves located near the metropolitan center. The latter is an example of deliberate human action and is the only instance of a simple linear urban-rural gradient effect seen in the data. In contrast to our findings for the urban sites, plant diversity was positively related to nearby housing age at the desert sites, with less floristically diverse sites tending to occur in block groups containing more recent housing developments, which we interpret as an inadvertent consequence of other factors (e.g., readily available land on flatter, lower elevation sites adjacent to lower diversity desert vegetation) on new housing development (51).

The spatial autocorrelation seen in plant diversity between desert sites was absent in the urban area. It would seem that in the intensively human-managed urban landscape there is an overall trend for plant diversity to be higher as nutrient and water availability increase due to fertilization and irrigation. This was reflected in higher generic richness (gamma diversity) as well as a much greater degree of compositional change from one site to another ( $\beta$ diversity) in the urban landscape compared with the desert (Table 2). However, spatial variation in the $\alpha$ diversity between individual sample sites would not seem to be a simple function of resource availability, as measured by soil $\mathrm{NO}_{3}-\mathrm{N}$, which made only a marginal contribution to predicting plant diversity in the models. Nor did the presence of impervious surface cover within the urban area seem to decrease plant diversity despite the accompanying reduction in growing surface area (due to the higher diversity per unit of cultivated surface area). However, urban sites that were formerly farmed had $57 \%$ fewer woody plant genera than locations that had never been cultivated. Complete removal of native vegetation before cultivation apparently depletes the local flora, creating a legacy effect that persists despite the subsequent creation of a vegetated urban landscape.

Our study is necessarily based on observational data, from which a causal relationship can only be implied and conclusions are necessarily limited to the scale at which the study was carried out. Different patterns may emerge with a higher spatial resolution or different grain size of the sample unit $(52,53)$. Given these caveats, it would seem that the urban-rural gradient paradigm may provide a suitable model to explain the effects of urbanizing "disturbances" on intact native vegetation communities. However, our results within the urban matrix suggest that human maintenance is modifying the traditional resource availability-diversity relationships, in which a greater number of limiting nutrients allows coexistence of a greater number of competing species (54). Humans remove resource limitations while simultaneously maintaining high diversity. We suggest that diversity in human-created habitats has less to do with variation in traditional limiting resources and more to do with human preferences for particular landscapes $(44,55,56)$ along with the availability of financial resources to realize those landscapes. The resource-diversity relationship then becomes one of financial 
rather than natural resources, interacting with land use, legacy effects, and other sociocultural factors. Our findings, albeit from a preliminary synoptic survey of a single metropolitan area, suggest that current and former land use, human resource abundance (i.e., wealth), and specific technocultural factors related to housing age are paramount. The positive relationship between plant diversity and wealth is particularly interesting, because it seems to mirror the well established link between quality of the social environment and socioeconomic status (57).

With our synoptic approach it is not possible to capture fully the interactions between the biophysical and socioeconomic variables, because people not only create landscapes with enhanced diversity but also may prefer to live where such landscapes already exist. Repeating our survey at regular intervals may allow us to determine the interactions between these factors and investigate how changes in income levels translate into

1. Pickett, S. T. A., Burch, W. R., Jr., Dalton, S., Foresman, T., Grove, J. M. \& Rowntree, R. (1997) Urban Ecosyst. 1, 185-199.

2. Grimm, N. B. Grove, J. M., Pickett, S. T. A. \& Redman, C. L. (2000) Bioscience 70, 571-584.

3. Vitousek, P. M., Mooney, H. A., Lubchenco, J. \& Melillo, J. M. (1997) Science 277, 494-499.

4. McDonnell, M. J. \& Pickett, S. T. A. (1993) Humans as Components of Ecosystems: The Ecology of Subtle Human Effects and Populated Areas (Springer, New York).

5. Collins, J. P., Kinzig, A. P., Grimm, N. B., Fagan, W. B., Hope, D., Wu, J. \& Borer, E. T. (2000) Am. Sci. 88, 416-425.

6. Kaiser, J. (2001) Science 293, 624-627.

7. Chesson, P. (2000) Theor. Popul. Biol. 58, 211-237.

8. Anderson, E. (1956) in Man's Role in Changing the Face of the Earth, ed. Thomas, W. L., Jr. (Univ. of Chicago Press, Chicago), pp. 763-777.

9. Whitney, G. G. \& Adams, S. D. (1980) J. Appl. Ecol. 17, 431-448.

10. McDonnell, M. J. \& Pickett, S. T. A. (1990) Ecology 71, 1232-1237.

11. McDonnell, M. J., Pickett, S. T. A. \& Pouyat, R. V. (1993) in Humans as Components of Ecosystems, eds. McDonnell, M. J. \& Pickett, S. T. A. (Springer, New York), pp. 175-189.

12. Blair, R. B. (1996) Ecol. Appl. 6, 506-519.

13. Clergeau, P., Savard, J. P. L., Mennechez, G. \& Falardeau, G. (1998) Condor 100, 413-425.

14. Alberti, M., Botsford, E. \& Cohen, A. (2001) in Avian Ecology and Conservation in an Urbanizing World, eds. Marzluff, J. M., Bowman, R. \& Donnelly, R. (Kluwer, Boston), pp. 89-115.

15. McDonnell, M. J., Pickett, S. T. A., Groffman, P., Bohlen, P., Pouyat, R., V., Zipperer, W. C., Parmelee, R. W., Carreiro, M. M. \& Medley, K. (1997) Urban Ecosyst. 1, 21-36.

16. Medley, K. E., McDonnell, M. J. \& Pickett, S. T. A. (1995) Prof. Geogr. 47, 159-168.

17. Pouyat, R. V., McDonnell, M. J. \& Pickett, S. T. A. (1995) J. Environ. Qual. 24, $516-526$.

18. Kent, M., Stevens, R. A. \& Zhang, L. (1999) J. Biogeogr. 26, 1281-1298.

19. Dana, E. D., Vivas, S. \& Mota, J. F. (2002) Landsc. Urban Plan. 59, 203-216.

20. Grove, J. M. \& Burch, W. R., Jr. (1997) Urban Ecosyst. 1, 259-275.

21. Dow, K. (2000) Urban Ecosyst. 4, 255-275.

22. Naveh, Z. (2000) Bioscience 50, 357-361.

23. Savard, J. L., Clergeau, P. \& Mennechez, G. (2000) Landsc. Urban Plan. 48, $131-142$.

24. Liu, J. (2001) Ecol. Modell. 140, 1-8.

25. Matson, P. A., Parton, W. J., Power, A. G. \& Swift, M. J. (1997) Science 277, 504-509.

26. McAuliffe, J. R. (1994) Ecol. Monogr. 64, 111-148.

27. Parker, K. C. \& Bendix, J. (1996) Phys. Geogr. 17, 113-141. changes in plant diversity over time. However, more detailed studies of the interplay among factors such as educational level, culture, institutional influences, and controls will also clearly be needed to understand fully the mechanisms determining how human choices drive urban plant diversity.

We thank Steven S. Carroll for the sampling design and carrying out the statistical analyses; M. Myers, A. Budet, S. Paine, M. Clary, A. Stiles, L. Stabler, and S. Holland for assistance in the field; Peter McCartney for help with database issues; Salt River Project for the donation of helicopter time; the Cities of Phoenix, Scottsdale, and Tempe, Maricopa County Parks, Tonto National Forest, Arizona State Lands Department, Sky Harbor Airport, and all the private property owners involved for giving us permission to access their land; and S. Collins, W. Schlesinger, M. Katti, and S. Fisher for comments on the manuscript. This work was funded by National Science Foundation Grant DEB-9714833.

28. Whittaker, R. H. \& Niering, W. A. (1975) Ecology 56, 771-790.

29. Shreve, F. (1951) Vegetation and Flora of the Sonoran Desert: Volume I, Vegetation (Carnegie Institute, Washington, DC), Vol. 591, pp. 1-192.

30. Turner, M. G. (1989) Annu. Rev. Ecol. Syst. 20, 171-197.

31. Turner, M. G. \& Gardner, R. (1991) Quantitative Methods in Landscape Ecology (Springer, New York).

32. Luck, M. A. \& Wu, J. (2002) Landsc. Ecol. 17, 327-339.

33. Stevens, D. L., Jr. (1994) J. Environ. Manage. 42, 1-29.

34. Stapanian, M. A., Sundberg, S. D., Baumgardner, G. A. \& Liston, A. (1998) Plant Ecol. 139, 49-62.

35. Stevens, D. L., Jr. (1997) Environmetrics 8, 167-195.

36. Peterson, S. A., Urquhart, N. S. \& Welch, E. B. (1999) Environ. Sci. Technol. 33, 1559-1565.

37. Maricopa Association of Governments (1997) Urban Atlas: Phoenix Metropolitan Area (Maricopa Association of Governments, Phoenix).

38. Knowles-Yánez, K., Moritz, C., Fry, J., Redman, C. L., Bucchin, M. \& McCartney, P. H. (1999) Central Arizona-Phoenix Long-Term Ecological Research Contribution No. 1 (Center for Environmental Studies, Arizona State Univ., Tempe).

39. Peterson, K. A., McDowell, L. B. \& Martin, C. A. (1999) HortScience 34, 491

40. Limerick, P. N. (1987) The Legacy of Conquest (Norton, New York).

41. Roy, D. B., Hill, M. O. \& Rothery, P. (1999) Ecography 22, 507-515.

42. Sukopp, H. (1990) in Urban Ecology: Plants and Plant Communities in Urban Environments, eds. Sukopp, H., Hejny, S. \& Kowarik, I. (SPB Academic, The Hague, The Netherlands), pp. 1-22.

43. Meyer, W. B. (1994) Urban Geogr. 15, 505-513.

44. Martin, C. A., Peterson, K. A. \& Stabler, L. B. (2003) J. Arboric. 29, 9-17.

45. Detwyler, T. R. (1972) in Urbanization and Environment, eds. Detwyler, T. E. \& Marcus, M. G. (Duxbury, Belmont, CA), pp. 230-259.

46. Talarchek, G. M. (1990) Urban Geogr. 11, 65-86.

47. Iverson, L. R. \& Cook, E. A. (2000) Urban Ecosyst. 4, 105-124.

48. Martin, C. A. (2001) Desert Plants 17, 26-31.

49. Fraser, E. D. G. \& Kenney, W. A. (2000) J. Arboric. 26, 106-112.

50. Wondzell, S. M., Cunningham, G. L. \& Bachelet, D. (1996) Landsc. Ecol. 11, 351-362.

51. Fagan, W. F., Meir, E., Carroll, S. S. \& Wu, J. (2001) Landsc. Ecol. 16, 33-39.

52. Qi, Y. \& Wu, J. (1996) Landsc. Ecol. 11, 39-49.

53. Jelinski, D. E. \& Wu, J. G. (1996) Landsc. Ecol. 11, 129-140.

54. Tilman, D. (1977) Ecolology 58, 338-348.

55. Ulrich, R. S. (1986) Landsc. Urban. Plan. 13, 29-44.

56. Ulrich, R. S. (1993) in The Biophilia Hypothesis, eds. Kellert, S. R. \& Wilson, E. O. (Island, Washington, DC), pp. 73-137.

57. Nelson, A. L., Schwirian, K. P. \& Schwirian, P. (1998) Soc. Sci. Res. 27, $410-431$. 